Pesq. Vet. Bras. 37(12):1395-1400, dezembro 2017 DOI 10.1590/S0100-736X2017001200006

\title{
Susceptibilidade de duas linhagens comerciais de frango de corte no desenvolvimento de dermatite necrótica e possível relação dos genes iss e iutA de Escherichia coli com a reprodução experimental da doença ${ }^{1}$
}

\author{
Daiane Carvalho², Thiago M. Tejkowski², Fátima R.F. Jaenisch ${ }^{3}$, Rogério 0. \\ Rodrigues $^{4}$, Kelly C.T. Brito ${ }^{2}$ e Benito G. Brito ${ }^{2 *}$
}

\begin{abstract}
Carvalho D., Tejkowski T.M., Jaenish F.R.F., Rodrigues R.O., Brito K.C.T. \& Brito B.G. 2017. [Susceptibility of two commercial lineages of broilers in the development of necrotic dermatitis and relationship of iss and iutA genes from Escherichia coli with the experimental reproduction of the disease.] Susceptibilidade de duas linhagens comerciais de frango de corte no desenvolvimento de dermatite necrótica e possível relação dos genes iss e iutA de Escherichia coli com a reprodução experimental da doença. Pesquisa Veterinária Brasileira 37(12):1395-1400. Laboratório de Saúde das Aves e Inovação Tecnológica, Instituto de Pesquisas Veterinárias Desidério Finamor, Fundação Estadual de Pesquisa Agropecuária, Estrada do Conde 6000, Eldorado do Sul, Sans Souci, RS 92990000, Brazil. E-mail: benitobrito@gmail.com

Avian cellulitis is a disease of great importance for the global poultry industry, being mainly related to Escherichia coli. In this study the susceptibility of two lineages of broilers in the development of cellulite was compared to the challenge with different concentrations of $E$. coli. In addition, it evaluated the relationship of the iss and iutA genes with pathogenicity of $E$. coli samples from different origins (fecal/clinical cases) in chicks and with the experimental reproduction of disease in 35-day-old broilers. By inoculating broilers (Cobb/ Ross) with different levels of challenge $\left(10^{5}-10^{8} \mathrm{CFU} / \mathrm{mL}\right)$ of $E$. coli, no significant differences had been observed between strains for sensitivity to necrotic dermatitis for the same dosage $(\mathrm{p} \leq 0.05)$. Detection of the iss and iutA genes showed that they were only present in samples from clinical cases. Likewise, these strains were considered high pathogenicity for chickens $\left(>80 \%\right.$ lethality), leading to the formation of more extensive lesion areas $\left(\geq 3 \mathrm{~cm}^{2}\right)$ at 35 days of birds compared to the samples from fecal origin $(p \leq 0.05)$. Still, the differences with respect to lesion size were also found among isolates of the same origin $(p \leq 0,05)$. Thus, the lineage can not be considered a primary factor in the development of necrotic dermatitis in broilers. Furthermore, it is suggested that iss and iutA genes, when present together or separately, could be considered as virulence markers for $E$. coli strains that cause avian cellulite.
\end{abstract}

INDEX TERMS: Dermatitis, iss gene, iutA gene, Escherichia coli, avian cellulitis, poultry, lineage broiler, virulence genes

\footnotetext{
${ }^{1}$ Recebido em 29 de junho de 2016.

Aceito para publicação em 19 de abril de 2017.

${ }^{2}$ Laboratório de Saúde das Aves e Inovação Tecnológica (LSAIT), Instituto de Pesquisas Veterinárias Desidério Finamor (IPVDF), Fundação Estadual de Pesquisa Agropecuária (FEPAGRO), Estrada do Conde 6000, Eldorado do Sul, Sans Souci, RS 92990-000, Brasil. *Autor para correspondência: benitobrito@gmail.com

Laboratório de Patologia, Embrapa Suínos e Aves, Rodovia BR-153 Km 10, Cx. Postal 21, Concórdia, SC 89700-000, Brasil.

${ }^{4}$ Laboratório de Leptospirose, IPVDF, FEPAGRO. Estrada Municipal do Conde 6000, Eldorado do Sul, RS 92990-000, Brasil.
}

RESUMO.- Celulite aviária é uma enfermidade de grande importância para a avicultura mundial, sendo relacionada principalmente à Escherichia coli (E. coli). Neste estudo foi comparada a susceptibilidade de duas linhagens de aves no desenvolvimento da celulite diante do desafio com diferentes concentrações de E. coli. Além disso, foi avaliada a relação dos genes iss e iutA com a patogenicidade de amostras de $E$. coli de diferentes origens (fecal/casos clínicos) em pintinhos e com a reprodução experimental da doença em aves de 35 dias de idade. Através da inoculação de frangos 
de corte (Cobb/Ross) com diferentes níveis de desafio $\left(10^{5}\right.$ a $10^{8} \mathrm{UFC} / \mathrm{mL}$ ) de E. coli, não foram observadas diferenças significativas entre as linhagens quanto à sensibilidade à dermatite necrótica para a mesma dosagem $(p \leq 0,05)$. A detecção dos genes iss e iutA demonstrou que estes estiveram presentes somente nas amostras provenientes de casos clínicos. Da mesma forma, estes isolados foram considerados de alta patogenicidade para pintinhos $(>80 \%$ letalidade), levando a formação de áreas de lesão mais extensas $\left(\geq 3 \mathrm{~cm}^{2}\right)$ em aves de 35 dias, quando comparado às amostras de origem fecal $(p \leq 0,05)$. Ainda, as diferenças com relação ao tamanho de lesão foram constatadas também entre os isolados de mesma origem $(p \leq 0,05)$. Desta forma, a linhagem não pode ser considerada um fator primordial para o desenvolvimento de dermatite necrótica em frangos. Ainda, sugere-se que os genes iss e iutA, quando presentes em conjunto ou isoladamente, poderiam ser considerados marcadores de virulência em cepas de $E$. coli causadoras de celulite aviária.

TERMOS DE INDEXAÇ̃̃O: Dermatite necrótica, gene iss, gene iutA, Escherichia coli, celulite aviária, avicultura, linhagem frango de corte, genes de virulência.

\section{INTRODUÇÃO}

A Escherichia coli patogênica para as aves (APEC) está dentro do grupo das E. coli patogênicas extra-intestinais (ExPEC), sendo responsáveis por quadros de síndrome da cabeça inchada, coligranuloma, onfalite e dermatite necrótica, também conhecida como celulite aviária (Nolan et al. 2013, Kunert Filho et al. 2015). Segundo dados do Ministério da Agricultura Pecuária e Abastecimento (MAPA 2015), em 2014 foi estimado que aproximadamente $0,6 \%$ das condenações totais e $8 \%$ das condenações parciais de carcaças de frango foram em decorrência desta enfermidade. Em termos financeiros, estes dados representam para indústria brasileira um prejuízo de aproximadamente um milhão de dólares com condenações totais e 9,6 milhões de dólares com condenações parciais. Tendo em vista que o Brasil é o segundo maior produtor de carne de frango do mundo e o principal exportador (ABPA 2016), estes percentuais passam a ter grande expressão. Não obstante, ao longo dos anos, observou-se um aumento gradativo nas condenações totais e parciais nos abatedouros de todo o país em função da celulite aviária, caracterizando esta como uma das principais causas de condenação de carcaça da atualidade (Ferreira et al. 2012, Paschoal et al. 2012, Brasil 2015).

Esta doença é caracterizada como uma inflamação purulenta, aguda e difusa do tecido subcutâneo profundo que envolve camadas celulares, havendo a formação de placas fibrino-caseosas e algumas vezes estendendo-se a musculatura (Fallavena et al. 2000, Johnson et al. 2001). Um dos grandes problemas da enfermidade é o fato de que os sinais clínicos geralmente não são detectados durante o período de criação. As lesões são observadas somente no momento do abate, quando as penas são retiradas (Messier et al. 1993).

Dentre os principais fatores de risco, é conhecido que a solução de continuidade na pele causada por traumas facilita a penetração do patógeno e instalação do quadro infeccioso no tecido subcutâneo (Quel et al. 2013). Levantamentos epidemiológicos anteriores, bem como estudos de reprodução experimental verificaram que a $E$. coli é de fato o principal microrganismo relacionado a esta enfermidade (Norton 1997, Singer et al. 2000, Brito et al. 2003). Porém, apesar da importância da celulite aviária no âmbito mundial, ainda há uma carência de estudos mais complexos avaliando a sensibilidade de distintas linhagens de frango de corte no desenvolvimento da doença. Outro ponto a ser destacado, é com relação a amostras de E. coli isoladas de microbiota intestinal de aves sadias, das quais muitas vezes o potencial para causar doença é desconhecido ou subestimado.

Isolados de E. coli causadores de quadros de celulite são dotados e expressam fatores de virulência comuns a cepas isoladas de outras lesões de colibacilose (Brito et al. 2003). Apesar de não completamente elucidado o mecanismo de virulência, está comprovado cientificamente que alguns genes são mais frequentes em APEC e, portanto, podem estar relacionados ao desenvolvimento da celulite aviária. Dentre estes, destacam-se os genes iss e iutA, os quais são responsáveis, respectivamente, pela resistência da bactéria ao sistema complemento e por funcionar como receptor do sideróforo aerobactina (Johnson et al. 2008a, Johnson et al. 2008b, Barbieri et al. 2013).

Em relação ao exposto, este trabalho teve como objetivo comparar a susceptibilidade de duas linhagens de frangos de corte no desenvolvimento de lesões de celulite diante de diferentes concentrações de desafio. Além disso, foi avaliada a relação dos genes iss e iutA com a patogenicidade de amostras de E. coli de origem fecal (microbiota intestinal de aves sadias) e de casos clínicos de dermatite necrótica, pela detecção da letalidade em pintinhos de um dia e de lesões em frangos de 35 dias.

\section{MATERIAL E MÉTODOS}

Local de estudo. Este estudo foi desenvolvido nas unidades experimentais e no Laboratório de Saúde das Aves e Inovação Tecnológica (LSAIT) do Instituto de Pesquisas Veterinárias Desidério Finamor (IPVDF), sendo aprovado pelo Comitê de Biossegurança da instituição sob protocolo CIB 001/07.

Comparação de duas linhagens quanto à sensibilidade para desenvolvimento de dermatite necrótica. Foram utilizados 200 pintinhos machos com um dia de idade, sendo 100 da linhagem Cobb e 100 da linhagem Ross. Cada linhagem foi alojada em uma sala climatizada, com iluminação artificial e as aves distribuídas em camas de maravalha. Todas as aves receberam água e ração "ad libitum" durante todo o período experimental. Aos 35 dias de idade cada linhagem foi submetida a cinco tratamentos: o grupo 1 (controle) inoculado com $1 \mathrm{~mL}$ de solução salina, o grupo 2 foi desafiado com uma dose de $10^{8} \mathrm{UFC} / \mathrm{mL}$, o grupo 3 com $10^{7} \mathrm{UFC} / \mathrm{mL}$, o grupo 4 com $10^{6} \mathrm{UFC} / \mathrm{mL}$ e o grupo 5 recebeu $10^{5} \mathrm{UFC} / \mathrm{mL}$. A cepa utilizada no tratamento dos grupos $2,3,4$ e 5 correspondeu a uma amostra virulenta de E. coli (BK 466), anteriormente isolada de uma lesão de celulite em uma carcaça de matadouro-frigorífico. As doses dos desafios foram escolhidas com base na experiência do grupo de pesquisa com APEC e eram padronizadas a partir da cultura overnight da bactéria para o volume de $1 \mathrm{~mL}$ a ser inoculado. A via de administração empregada foi subcutânea na região peitoral. Para cada tratamento foram utilizadas 20 aves e, no grupo controle 20 aves. Após três dias do 
desafio, foi realizada a eutanásia mediante deslocamento cervical e, posteriormente, realizada a necropsia. As lesões de dermatite necrótica foram classificadas conforme Peighambari et al. (1995), os quais estabeleceram um escore de lesão de celulite aviária considerando a coloração, o tamanho e a presença de hemorragias.

Detecção dos genes iss e iutA de Escherichia coli e sua relação com a reprodução experimental de dermatite necrótica. Nesta etapa do estudo foram avaliadas 10 cepas de E. coli, sendo cinco isoladas do conteúdo intestinal de aves sadias (BK353, BK 357, BK 360, BK 362, BK 363) e cinco de lesões de celulite provenientes de carcaças de matadouro-frigorífico (BK 302, BK 466, BK 326 , BK 337, BK 346). Cada cepa foi caracterizada quanto presença/ausência dos genes de virulência iss e iutA. A escolha destes genes teve como base a sua importância na instalação e manutenção sistêmica da bactéria no organismo das aves. Brevemente, o DNA das amostras foi extraído pela técnica de lise térmica, como descrito previamente por Johnson \& Stell (2000). A reação de PCR, bem como os primers utilizados, seguiram a metodologia proposta por Johnson et al. (2008a).

Além da caracterização molecular, estes isolados foram avaliados quanto ao grau de patogenicidade por bioensaios em pintinhos machos Cobb de um dia de idade, conforme Carvalho et al. (2015). O critério para escolha desta linhagem foi baseado nos resultados obtidos na primeira parte do estudo somado a facilidade de aquisição das aves em relação à linhagem Ross. Para tanto, grupos de 10 aves cada foram inoculados via subcutânea na região esquerda da cavidade peritoneal com $0,1 \mathrm{~mL}\left(\sim 1,5 \times 10^{7}\right.$ UFC) de uma cultura overnight padronizada a 0,5 na escala de Mac Farland contendo $\sim 1,5 \times 10^{8} \mathrm{UFC} / \mathrm{mL}$ de cada amostra. 0 grupo controle foi inoculado com o mesmo volume de solução salina. Ao longo de cinco dias, as aves foram acompanhadas e avaliado o percentual de letalidade, parâmetro este utilizado para classificação das cepas como sendo de patogenicidade alta ( $\geq 80 \%$ de letalidade), intermediária ( $\geq 50$ a $<80 \%$ de letalidade), baixa $(<50 \%$ de letalidade) ou apatogênica (ausência de letalidade). Foram consideradas amostras APEC aquelas que levassem a letalidade pelo menos uma ave do grupo.

Estabelecida a patogenicidade das cepas em pintinhos, realizou-se uma inoculação em frangos de corte Cobb aos 35 dias de idade. A escolha desta linhagem seguiu os mesmos critérios mencionados acima. Foram utilizados 250 frangos, divididos em 10 grupos com 20 aves cada. Cada grupo foi desafiado com $10^{6}$ UFC/mL de uma das cepas, via subcutânea do lado esquerdo do peito. Para cada grupo tratado, foram utilizadas cinco aves como controle, sendo essas inoculadas com o mesmo volume de solução salina. Após três dias, foi realizado o sacrifício e a necropsia das aves. As lesões compatíveis com quadros de celulite foram classificadas quanto à área de lesão produzida com a utilização de uma régua calibrada $\left(\mathrm{cm}^{2}\right)$.

Análise estatística. As variáveis que representavam o grau de lesão foram descritas pela mediana e transformadas em raiz quadrada. Posteriormente, os dados foram analisados pelo teste de Wilcoxon para comparação da área de lesão entre as diferentes concentrações do inóculo dentro de cada linhagem. A fim de se verificar possíveis diferenças entre linhagens utilizou-se o teste de Kruskal-Wallis.

Visando a comparação dos isolados quanto à origem, primeiramente foi realizada a distinção de uma reação inespecífica em relação à lesão de celulite propriamente dita. Para tanto, calculou-se a média da área de lesão ocasionada pelas cepas de origem fecal, estipulando-se assim um ponto de corte. Posteriormente, aplicou-se a seguinte fórmula: (Média da área de lesão dos isolados de origem fecal $\left(\mathrm{cm}^{2}\right)$ - valor individual de lesão $\left(\mathrm{cm}^{2}\right)$ por ave inoculada)/Média da área de lesão dos isolados de origem fecal $\left(\mathrm{cm}^{2}\right)$. Em seguida, aplicou-se o teste Qui-quadrado. A fim de se comparar os isolados de mesma origem utilizou-se o teste de McNemar. Todas as análises foram realizadas utilizando-se o software PASW Statistics 18 (SPSS, Chicago, IL, USA), considerando-se um nível de significância de 5\%.

\section{RESULTADOS}

Conforme demonstrado no Quadro 1, as duas linhagens de frango de corte demonstraram lesões de dermatite necrótica de intensidade similar e crescente, de acordo com a concentração bacteriana utilizada. As dosagens de $10^{8} \mathrm{e}$ $10^{7} \mathrm{UFC} / \mathrm{mL}$ reproduziram lesões de grau severo a moderado para quase a totalidade das aves. No desafio de $10^{6}$ UFC/mL observou-se que 11 das 20 aves do grupo tratado pertencentes à linhagem Cobb e 12 da linhagem Ross apresentaram nível moderado de lesão. Para $10^{5} \mathrm{UFC} / \mathrm{mL}$ foi verificado, de modo geral, o desenvolvimento de lesões com intensidade mais branda quando comparado às demais doses inoculadas, sendo que 12 e 11 aves das linhagens Cobb e Ross, respectivamente, apresentaram celulite em grau leve. A Figura 1 representa os graus de lesão de celulite aviária observados nos dois grupos de aves inoculados.

Além disso, com relação à área de lesão produzida, foi possível observar que com a redução da concentração do
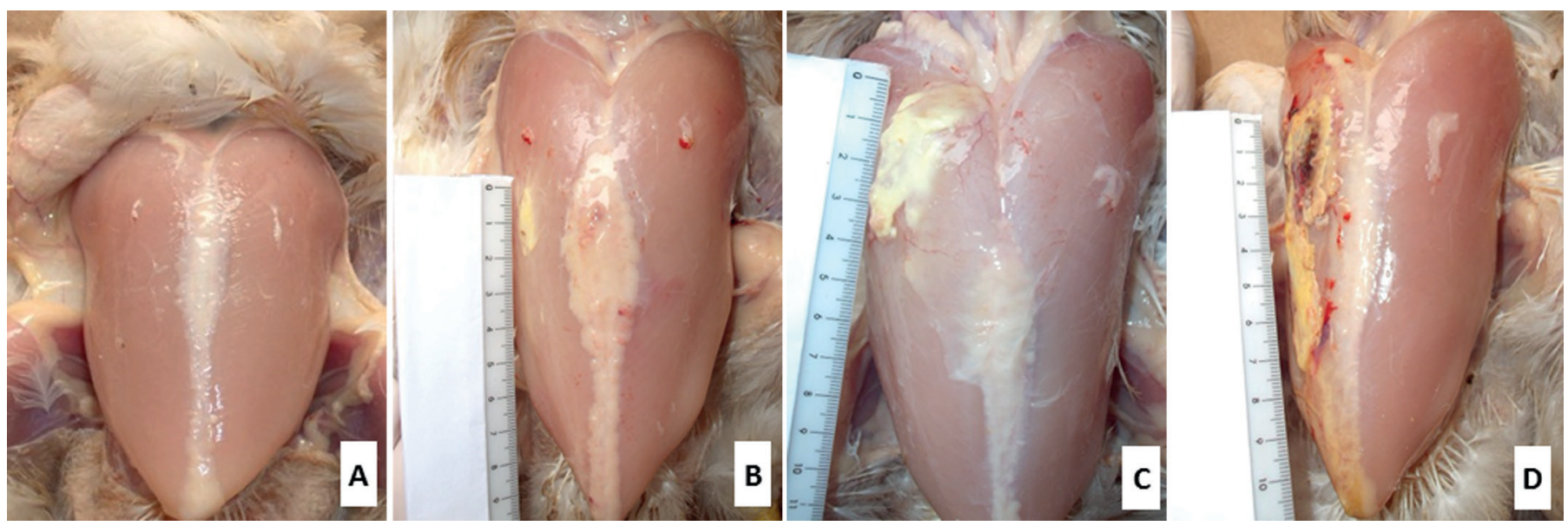

Fig.1. Classificação dos graus de lesão de dermatite necrótica de acordo com Peighambari et al. (1995). (A) Sem lesão, (B) grau leve, (C) grau moderado, (D) grau severo de lesão. 
Quadro 1. Suscetibilidade das linhagens Cobb e Ross a diferentes concentrações do desafio por Escherichia coli $\left(10^{5}\right.$ a $\left.10^{8} \mathrm{UFC} / \mathrm{mL}\right)$ e avaliação do grau (Peighambari et al. 1995) e área da lesão

\begin{tabular}{|c|c|c|c|c|c|c|c|c|}
\hline \multirow[t]{3}{*}{ Grau de lesão } & \multicolumn{8}{|c|}{ Dose do desafio (UFC/mL) } \\
\hline & \multicolumn{2}{|c|}{$10^{8}$} & \multicolumn{2}{|c|}{$10^{7}$} & \multicolumn{2}{|c|}{$10^{6}$} & \multicolumn{2}{|c|}{$10^{5}$} \\
\hline & Cobb & Ross & Cobb & Ross & Cobb & Ross & Cobb & Ross \\
\hline Severo & 12 & 15 & 13 & 15 & 5 & 4 & 1 & 1 \\
\hline Moderado & 8 & 5 & 6 & 4 & 11 & 12 & 7 & 8 \\
\hline Leve & 0 & 0 & 1 & 1 & 4 & 4 & 12 & 11 \\
\hline Total (aves) & 20 & 20 & 20 & 20 & 20 & 20 & 20 & 20 \\
\hline *Mediana da área de lesão $\left(\mathrm{cm}^{2}\right)^{* *}$ & $4,05^{\mathrm{a}}$ & $4,12^{\mathrm{a}}$ & $3,64^{\text {ad }}$ & $3,74^{\mathrm{a}}$ & $2,60^{\mathrm{bd}}$ & $2,64^{\mathrm{b}}$ & $1,93^{c}$ & $1,64^{c}$ \\
\hline
\end{tabular}

*Valores com letras iguais na mesma linha não diferem significativamente entre si $(p \leq 0,05),{ }^{* *}$ Dados transformados em raiz quadrada.

Quadro 2. Características das cepas de Escherichia coli quanto a origem (celulite/ fecal), presença/ausência dos genes iss e iutA, grau de patogenicidade, número de aves com lesão de celulite e o valor médio da área de lesão

\begin{tabular}{|c|c|c|c|c|c|}
\hline Amostra & Origem & $\begin{array}{c}\text { Fator de } \\
\text { virulência }\end{array}$ & $\begin{array}{l}\text { Patogenicidade } \\
\text { em pintinhos }\end{array}$ & $\begin{array}{c}\text { № aves com lesão } \\
\text { de celulite }(\geq 3 \mathrm{~cm} 2)^{*}\end{array}$ & $\begin{array}{l}\text { Valor médio da área } \\
\text { de lesão }(\mathrm{cm} 2)^{* *}\end{array}$ \\
\hline BK 326 & Celulite $^{a}$ & iss + /iutA+ & PA & $15 / 20^{\mathrm{ab}}$ & 5,43 \\
\hline BK 337 & & iss $+/$ iutA+ & PA & $18 / 20^{\mathrm{bc}}$ & 7,66 \\
\hline BK 466 & & iss $+/$ iutA+ & PA & $16 / 20^{\text {ac }}$ & 5,66 \\
\hline ВК 302 & & iss + / iutA- & PA & $10 / 20^{\mathrm{d}}$ & 2,96 \\
\hline BK 346 & & iss - / iutA+ & PA & $5 / 20^{\mathrm{e}}$ & 2,05 \\
\hline BK353 & Fecal $^{\text {b }}$ & iss - / iutA- & $\mathrm{AP}$ & $9 / 20^{\mathrm{ab}}$ & 0,89 \\
\hline BK 357 & & iss - / iutA- & $\mathrm{AP}$ & $8 / 20^{\text {ade }}$ & 1,40 \\
\hline BК 360 & & iss - / iutA- & PB & $0 / 20^{\mathrm{bcdf}}$ & $-1,11$ \\
\hline BK 362 & & iss - / iutA- & $\mathrm{AP}$ & $1 / 20^{c}$ & $-2,45$ \\
\hline BK 363 & & iss - / iutA- & PB & $5 / 20^{\text {ef }}$ & 0,33 \\
\hline
\end{tabular}

$\overline{\mathrm{PA}}=$ Alta patogenicidade, $\mathrm{PB}=$ Baixa patogenicidade, $\mathrm{AP}=$ Apatogênico; ${ }^{*}$ Letras iguais na mesma coluna dentro de mesmo grupo de origem não diferem significativamente entre si $(\mathrm{p} \leq 0,05)$, ** Média do valor de área de lesão corrigido de cada cepa.

inóculo, a extensão tecidual acometida também foi menor, independente da linhagem estudada. Ao compararmos os níveis de desafio para cada linhagem (Quadro 1), não foi constatada diferença significativa para as dosagens de $10^{7}$ e $10^{8} \mathrm{UFC} / \mathrm{mL}$. Porém, comparando estas mais altas concentrações com a dose de $10^{5} \mathrm{UFC} / \mathrm{mL}$, foi verificado que a área de lesão observada reduziu significativamente nas duas linhagens. Da mesma forma, a dosagem de $10^{6} \mathrm{UFC} / \mathrm{mL}$ resultou em lesões de menor proporção quando comparado a $10^{7}$ e $10^{8} \mathrm{UFC} / \mathrm{mL}$ para a linhagem Ross, e apenas a $10^{8} \mathrm{UFC} / \mathrm{mL}$ para a linhagem Cobb $(\mathrm{p} \leq 0,005)$. Não foi verificada diferença estatística para o mesmo desafio entre as linhagens.

De acordo com o Quadro 2, as cepas de E. coli provenientes de quadros de celulite foram caracterizadas por possuir um ou os dois genes pesquisados, sendo na sua totalidade consideradas patogênicas para pintinhos. Tendo em vista o valor encontrado e utilizado como ponto de corte para distinção de uma reação inespecífica e a lesão propriamente dita como $\geq 3 \mathrm{~cm}^{2}$, quatro dos cinco isolados de celulite levaram ao desenvolvimento de lesões compatíveis com dermatite necrótica em $50 \%$ ou mais das aves de 35 dias. Também foi verificado um menor número de aves acometidas para a amostra onde o gene responsável pela resistência sérica estava ausente (5/20). Os valores médios da área tecidual atingida, dentre os isolados onde os genes iss e iutA estavam presentes, foram superiores $\left(>5 \mathrm{~cm}^{2}\right)$ àqueles verificados nas cepas onde um desses fatores de virulência era ausente $\left(<3 \mathrm{~cm}^{2}\right)$.
Com relação aos isolados de origem fecal, nenhum dos genes pesquisados neste estudo foi detectado. Ainda, estas cepas mostraram-se como sendo de patogenicidade baixa ou apatogênicas quando inoculadas em pintinhos de um dia de idade, e em aves de 35 dias menos de $50 \%$ das aves desenvolveram lesões de dermatite necrótica. Quando as lesões ocorreram, o valor de área ficou muito próximo ao valor crítico, levando a uma média inferior quando comparada aos isolados originários de celulite (Quadro 2).

Com relação ao número de aves que apresentaram lesões de celulite, cabe destacar que houve diferença significativa entre os grupos de amostras de casos clínicos e de origem fecal $(\mathrm{p} \leq 0,05)$. Da mesma forma, evidenciou-se diferença entre os isolados de mesma origem quanto ao número de aves com lesões ( $\mathrm{p} \leq 0,05)$ (Quadro 2).

\section{DISCUSSÃO}

Constatou-se que Escherichia coli foi capaz de reproduzir lesões de celulite aviária nas duas linhagens de frango de corte avaliadas. Este achado está de acordo com outros autores, os quais afirmaram que a $E$. coli é de fato um patógeno relacionado a casos de dermatite necrótica em aves (Norton et al. 1999, Brito et al. 2003). Cabe ressaltar que, nas condições deste estudo, a linhagem do animal não influenciou na ocorrência de lesões de celulite, não podendo ser considerada como um fator primordial para o desenvolvimento da enfermidade em frangos. Trabalhos prévios avaliaram a influência de alguns fatores de risco para o apa- 
recimento de celulite aviária, dentre eles o tipo de cama, sexo, peso da ave, fonte do alimento, uso de bacitracina de zinco na alimentação, intervalo entre lotes e empenamento (Morris 1994, Elfadil et al. 1996). A sensibilidade de diferentes linhagens em relação à doença foi também abordada por Olkowski et al. (2005), porém comparando frango de corte e poedeira comercial. A comparação entre linhagens de corte realizada no presente estudo é precursora no âmbito da avicultura industrial.

Foi observada uma relação diretamente proporcional, onde, as doses inoculantes maiores ocasionaram lesões mais severas e extensas e com um maior o número de aves acometidas. Ainda, a cepa de E. coli testada foi capaz de induzir o desenvolvimento de celulite para todas as concentrações avaliadas em maior ou menor grau. Em função da grande importância econômica que a celulite aviária apresenta para a avicultura, estudos nos quais são realizadas inoculações experimentais de E. coli em aves, com o intuito de se avaliar a relação dose-resposta, vem sendo utilizados (Macklin et al. 2009, Nain \& Smits 2011, Allan et al. 2012). Nain \& Smits (2011) também constataram que a severidade da doença caiu linearmente com o decréscimo da dose, resultado este semelhante ao observado no presente trabalho. Chinivasagam et al. (2010) demonstraram que na cama dos aviários os níveis de E. coli podem variar entre $9.7 \times 10^{4}$ UFC/g a $4.2 \times 10^{5} \mathrm{UFC} / \mathrm{g}$, conforme sua reutilização. Segundo Carvalho et al. (2015), considerando que estes isolados de $E$. coli de origem fecal/ambiental podem apresentar capacidade patogênica, os resultados obtidos passam a ser de grande importância, visto que na dosagem de $10^{5} \mathrm{UFC} / \mathrm{mL}$ foi observado um grau de lesão variando basicamente entre leve a moderado. Schrader et al. (2004) afirmaram que no terço final da criação, os níveis de $E$. coli nos aviários é maior. Neste período ocorre um aumento na densidade dos galpões, havendo um favorecimento a ocorrência de lesões cutâneas. Este fato aliado ao concomitante aumento na concentração de E. coli, oferece um maior risco no desenvolvimento da celulite aviária.

Foi evidenciada uma forte relação entre o genótipo (presença/ausência dos genes) e o fenótipo (grau de patogenicidade e extensão das lesões) das cepas de E. coli avaliadas. Os genes pesquisados estiveram presentes exclusivamente nos isolados oriundos de casos clínicos, os quais se mostraram como sendo de alta patogenicidade em pintinhos e ocasionando lesões de maior área em frangos. $\mathrm{O}$ oposto foi observado nas amostras de origem fecal, onde nenhuma delas apresentou os genes, sendo classificadas como apatogênicas ou de baixa patogenicidade em pintinhos. $\mathrm{O}$ número de aves adultas acometidas para três dos cinco isolados de origem fecal foi igual ou superior a cinco, tendo, portanto, comportamento semelhante às cepas provenientes de celulite. Porém, cabe ressaltar que a média do tamanho da lesão ficou abaixo do ponto de corte estipulado. Uma possível explicação para este achado é o fato de que a ausência dos genes responsáveis pela manutenção da bactéria no local da infecção e pela captação de ferro podem ter tornado a infecção auto-limitante, fazendo com que o animal apresentasse apenas uma reação inflamatória no local da inoculação.
Neste estudo evidenciou-se que as amostras de $E$. coli de origem fecal utilizadas não representaram risco potencial para o desenvolvimento de celulite em aves. Contudo, Piatti \& Baldassi (2007) relataram a presença de sorotipos de $E$. coli patogênicas na microbiota intestinal e outros órgãos de aves sadias, como o sorotipo 078, o qual é considerado um dos principais relacionados ao aparecimento de quadros de colibacilose e celulite em aves. Jeffrey et al. (2002) evidenciaram que os sorotipos mais prevalentes causadores da dermatite necrótica são 02, 078 e 036.

0 fato de os genes de virulência estarem presentes somente nos isolados originários de celulite está de acordo com o observado por Delicato et al. (2003) e Barbieri et al. (2015), os quais verificaram que os genes iut A e iss estão dentre os encontrados com maior frequência nos isolados obtidos de colibacilose do que nos isolados provenientes de amostras fecais de aves sadias. Vieira et al. (2014) observaram mais de $60 \%$ de positividade para o gene iss em amostras de celulite, sendo sua presença considerada um forte marcador de virulência em estirpes patogênicas para aves. Da mesma forma, Schouler et al. (2012) relataram que o gene iutA está presente em mais de $80 \%$ de isolados de E. coli patogênicos. Estes dados demonstram que os genes de virulência participam na patogenia da colibacilose, favorecendo a instalação e manutenção do quadro infeccioso no hospedeiro. Apesar de trabalhos anteriores relatarem uma alta diversidade genética de virulência e patogenicidade de APEC (Schouler et al. 2012), com os resultados encontrados neste estudo, pode-se sugerir que os genes iss e iutA, quando presentes simultaneamente, tornam a bactéria mais apta ao desenvolvimento de dermatite necrótica.

Ainda, dentre as amostras de mesma origem, foi verificada que houve diferenças significativas quanto ao número de aves acometidas pela doença. No caso dos isolados de celulite, este achado está de acordo ao observado por Peighambari et al. (1995), os quais afirmaram que dentre estirpes de casos clínicos algumas são mais propensas a causar a enfermidade do que outras.

\section{CONCLUSÕES}

Os modelos de reprodução experimental de dermatite necrótica com amostras APEC brasileiras permitiram diferenciar a patogenicidade das cepas de E. coli relacionadas a casos de celulite. Tais resultados são de grande importância para indústria avícola brasileira, pois possibilitam testes com produtos ou processos que visem reduzir a ocorrência desta enfermidade.

Baseado nos resultados encontrados, pode-se sugerir que os genes iutA e iss podem servir como marcadores moleculares de virulência para diferenciação de cepas causadoras de dermatite necrótica em frangos.

A associação destes dois genes ocasionou lesões de maior severidade, comprovando a característica multifatorial desta doença. Não foram evidenciadas diferenças entre as linhagens de frangos de corte quanto à sensibilidade no desenvolvimento de celulite.

Foi possível observar uma relação direta entre concentração bacteriana do desafio e tamanho de lesão na ave. 
Agradecimentos.- Ao CNPq (Conselho Nacional de Desenvolvimento Científico e Tecnológico) e Finep (Financiadora de Estudos e Projetos), pela concessão de bolsas e auxílio financeiro.

\section{REFERÊNCIAS}

ABPA 2016. Relatório Anual, Associação Brasileira de Proteína Animal, União Brasileira de Avicultura, p.133.

Allan B., Buchanan R.M., Hauta S., Den Hurk J.V. \& Wilson H.L. 2012. Innate immune cocktail partially protects broilers against cellulitis and septicemia. Avian Dis. 56(4):659-669.

Barbieri N.L., Oliveira A.L., Tejkowski T.M., Pavanelo D.B., Rocha D.A., Matter L.B., Callegari-Jacques S.M., Brito B.G. \& Horn F. 2013. Genotypes and pathogenicity of cellulitis isolates reveal traits that modulate APEC virulence. PloS one 8(80), doi.org/10.1371/journal.pone.0072322

Barbieri N.L., Oliveira A.L., Tejkowski T.M., Pavanelo D.B., Matter L.B., Pinheiro S.R.S., Vaz T.M.I., Nolan L.K., Logue C.M., Brito B.G. \& Horn F. 2015. Molecular characterization and clonal relationships among Escherichia coli strains isolated from broiler chickens with colisepticemia. Foodborne Pathog. Dis. 12(1):74-83.

Brito B.G., Gazari L.C.J. \& Vidotto M.C. 2003. Virulence factors and clonal relationships among Escherichia coli strains isolated from broiler chickens with cellulitis. Infect. Immun. 71(7):4175-4177.

Carvalho D., Finkler F., Grassotti T.T., Kunert Filho H.C., Lima F.E.S., Soares B.D., Rossato J.M., Cunha A.C., Brito K.C.T. \& Brito B.G. 2015. Antimicrobial susceptibility and pathogenicity of Escherichia coli strains of environmental origin. Ciênc. Rural 45(7):1246-1255.

Chinivasagam H.N., Redding M., Runge G. \& Blackall P.J. 2010. Presence and incidence of foodborne pathogens in Australian chicken litter. Brit. Poult. Sci. 51(3):311-318.

Delicato E.R., Brito B.G., Gazari L.C.J. \& Vidotto M.C. 2003. Virulence-associated genes in Escherichia coli isolates from poultry with colibacillosis. Vet. Microbiol. 94(2):97-103.

Elfadil A.A., Vaillancourt J.P. \& Meek A.H. 1996. Farm management risk factors associated with cellulitis in broiler chickens in Southern Ontario. Avian Dis. 40(3):699-706.

Fallavena L.C.B., Moraes H.L.S., Salle C.T.P., Silva A.B., Vargas R.S., Nascimento V.P. \& Canal C.W. 2000. Diagnosis of skin lesions in condemned or downgraded broiler carcasses - a microscopic and macroscopic study. Avian Pathol. 29(6):557-562.

Ferreira T.Z., Sesterhenn R. \& Kindlein L. 2012. Perdas econômicas das principais causas de condenações de carcaças de frangos de corte em matadouros-frigoríficos sob inspeção federal no Rio Grande do Sul, Brasil. Acta Sci. Vet. 40(1):1021.

Jeffrey J.S., Nolan L.K., Tonooka K.H., Wolfe S., Giddings C.W., Horne S.N., Foley S.L., Lynne A.M., Ebert J.O., Elijah L.M., Bjorklund G., Pfaff-McDonough S.J., Singer R.S. \& Doetkott C. 2002. Virulence Factors of Escherichia coli from Cellulitis or Colisepticemia Lesions in Chickens. Avian Dis. 46(1):48-52

Johnson J.R. \& Stell A.L. 2000. Extended virulence genotypes of Escherichia coli strains from patients with urosepsis in relation to phylogeny and host compromise. J. Infect. Dis. 181(1):261-272.

Johnson L.C., Bilgili S.F., Hoerr F.J.E.T., McMurtrey B.L. \& Norton R.A. 2001. The effects of early exposure of cellulitis-associated Escherichia coli in 1-day-old broiler chickens. Avian Pathol. 30(2):175-178.

Johnson T.J., Wannemuehler Y., Doetkott C., Johnson S.J., Rosenberger S.C. \& Nolan L.K. 2008a. Identification of Minimal Predictors of Avian Pathogenic Escherichia coli Virulence for Use as a Rapid Diagnostic Tool. J. Clin. Microbiol. 46(12):3987-3996.

Johnson T.J., Wannemuehler Y.M. \& Nolan L.K. 2008b. Evolution of the iss gene in Escherichia coli. Appl. Environ. Microbiol. 74(8):2360-2369.
Kunert Filho H.C., Carvalho D., Grassotti T.T., Soares B.D., Rossato J.M., Cunha A.C., Brito K.C.T., Cavalli L.S. \& Brito B.G. 2015. Avian Pathogenic Escherichia coli: methods for improved diagnosis. World's Poult. Sci. J. 71(2):249-258. Doi:10.1017/S0043933915000264

Macklin K.S., Norton R.A. \& Ewald S.J. 2009. Effect of the major histocompatibility complexo $\mathrm{n}$ the inhibition of induced cellulitis development in a broiler chicken model. Avian Dis. 53(2):297-300.

MAPA 2015. Serviço de Inspeção Federal, Ministério da Agricultura Pecuária e Abastecimento. <http://www.agricultura.gov.br/portal/page/ portal/Internet-MAPA/pagina-inicial/servicos-e sistemas/sistemas/ sif> Acesso em 10 abr. 2015.

Messier S., Quessy S., Robinson Y., Deveriese L.A., Hommez J. \& Fairbrother J.M. 1993. Focal dermatitis and cellulitis in broiler chickens: bacteriological and pathological findings. Avian Dis. 37(3):839-844.

Morris M.P. 1994. Broiler cellulitis update. Broiler Industry 3:36-39.

Nain S. \& Smits J.E.G. 2011. Validation of a disease model in Japanese quail (Coturnix coturnix japonica) with the use of Escherichia coli serogroup 02 isolated from a turkey. Can. J. Vet. Res. 75(3):171-175.

Nolan L.K., Barnes H.J., Vaillancourt J.R., Abdul-Aziz T. \& Logue C.M. 2013. Collibacilosis, p.1408. In: Swayne D.E., Glisson J.R., McDougald L.R., Nolan L.K., Suarez D.L. \& Nair V.L. (Eds), Diseases of Poultry. Wiley-Blackwell, Georgia.

Norton R.A. 1997. Avian cellulitis. World's Poult. Sci. J. 53(4):337-349.

Norton R.A., Macklin K.S. \& McMurtrey B.L. 1999. Evaluation of scratches as an essential element in the development of avian cellulitis in broiler chickens. Avian Dis. 43(2):320-325.

Olkowski A.A., Wojnarowicz C., Chirino-Trejo M., Wurtz B.M. \& Kumor L. 2005. The role of first line of defence mechanisms in the pathogenesis of cellulitis in broiler chickens: skin structural, physiological and cellular response factors. J. Vet. Med. A 52(10):517-524.

Paschoal E.C., Otutumi L.K. \& Silveira A.P. 2012. Principais causas de condenações no abate de frangos de corte de um abatedouro localizado na região noroeste do Paraná, Brasil. Arq. Ciênc. Vet. Zool. 15(2):93-97.

Peighambari S.M., Julian R.J., Vaillancourt J.P. \& Gyles C.L. 1995. Escherichia coli cellulitis: experimental infections in broiler chickens. Avian Dis. 39(1):125-134.

Piatti R.M. \& Baldassi L. 2007. Prevalência de Escherichia coli 078: K80 na microbiota de aves da região oeste do estado de São Paulo. Arqs Inst. Biológico, São Paulo, 74(4):357-359. (Comunicação Científica)

Quel N.G., Aragão A.Z.B., Salvadori M.R., Farias A.S., Joazeiro P.P., Santos L.M.B., Sá L.R.M., Ferreira A.J.P. \& Yano T. 2013. Cellulitis lesions in broiler chickens are induced by Escherichia coli vacuolating factor (ECVF). Vet. Microbiol. 162(2/4):866-872.

Schouler C., Schaeffer B., Brée A., Mora A., Dahbi G., Biet F., Oswald E., Mainil J., Blanco J. \& Moulin-Schouleur M. 2012. Diagnostic strategy for identifying avian pathogenic Escherichia coli based on four patterns of virulence genes. J. Clin. Microbiol. 50(5):1673-1678.

Schrader J.S., Singer R.S. \& Atwill E.R. 2004. A prospective study of management and litter variables associated with cellulitis in California broiler flocks. Avian Dis. 48(3):522-530.

Singer R.S., Jeffrey J.S., Carpenter T.E., Cooke C.L., Atwill E.R., Johnson W.O. \& Hirsh D.C. 2000. Persistence of cellulitis-associated Escherichia coli DNA fingerprints in successive broiler chicken flocks. Vet. Microbiol. 75(1):59-71.

Vieira T.B., Pereira V.L.A., Franco R.M., Nascimento E.R., Silva R.C.F. \& Tortelly R. 2014. Potencial patogênico e caráter séptico de Escherichia coli pela identificação dos fatores de virulência iss e felA em celulite e miúdos de frangos sob Inspeção Sanitária. Revta Bras. Med. Vet. 36(2):144152. 